\title{
Performance of Copper Electrode for Machining En-19 and Nickel Plated En-19 Alloy Steel by EDM
}

\author{
Mukesh Regmi ${ }^{1}$, Avinash Gupta ${ }^{2}$ \\ ${ }^{1}$ Visvesvaraya Technological University, Belgaum, India \\ ${ }^{2}$ Oklahoma State University, Oklahoma, USA \\ Email address: \\ mukesh.regmi@ncit.edu.np (M. Regmi)
}

\section{To cite this article:}

Mukesh Regmi, Avinash Gupta. Performance of Copper Electrode for Machining En-19 and Nickel Plated En-19 Alloy Steel by EDM. International Journal of Industrial and Manufacturing Systems Engineering. Vol. 2, No. 1, 2017, pp. 1-6. doi: 10.11648/j.ijimse.20170201.11

Received: May 8, 2016; Accepted: June 16, 2016; Published: March 28, 2017

\begin{abstract}
Electric discharge machining (EDM) is non-conventional machining processes that involves a transient spark discharges through the fluid due to the potential difference between the electrode and the work piece. The aim of this project is to determine the proper machining conditions for machining EN-19 and Nickel Plated EN-19 work pieces using electrical discharge machining (EDM). Basically, improper choice of parameter in EDM machine may result a few problems like the machine may cause of poor machining performance and it will decrease the accuracy of the products and incurs a lot of cost. The aim of this project is to determine the optimal machining parameters for machining work pieces using electrical discharge machining (EDM). Intensity of current, pulse on time and pulse of time were used as process parameters. This paper explores the characteristic of electric discharge machine (EDM) that is tool wear rate (TWR) and material removal rate (MRR) by using different workpiece materials namely En-19 and Nickel Plated En-19 alloy steel and copper as a tool material in order to increase the understanding of EDM processes. To achieve this project objective, an experimentation was done where the approach used was response surface methodology in which a well-designed experimental scheme named box behnken design was used to reduce the total number of experiments into 15 for each workpiece material. A second order empirical model is developed to predict the MRR and TWR. Finally ANOVA analysis is done to validate the model developed.
\end{abstract}

Keywords: EDM (Electric Discharge Machining), En-19, Nickel Plated En-19, MRR (Material Removal Rate), TWR (Tool Wear Rate), ANOVA (Analysis of Variance), RSM (Response Surface Methodology)

\section{Introduction}

Rapid technological advancements in the area of new materials and alloys with ever-increasing properties like strength, hardness, heat resistance, toughness and wear resistance have created many obstacles during machining of these materials by conventional machining process. So another choice of machining these materials has been into use known as non- conventional machining. These nonconventional machining processes may come into the equation for many reasons, the main are machinability, work piece shape, complexity, surface integrity and precision requirement. These processes are so called as they use new forms of energy and tools. Out of various non-conventional techniques of machining one most popular technique is Electric Discharge Machining (EDM) came into practice [1].

Electric Discharge Machining (EDM), sometimes colloquially also referred to as spark machining, die sinking or wire erosion, is an electro-thermal non-traditional machining process. Material is removed from the work piece by a series of rapidly recurring current discharges between two electrodes, separated by a dielectric liquid and subject to an electric voltage. The thermal energy of the sparks leads to intense heat conditions on the work piece causing melting and vaporizing of the work piece material. Due to a high temperature of the sparks, not only work material is melted and vaporized, but the electrode material is also melted and vaporized, which is known as tool wear [2].

As shown in the figure 1 there is the gap between tool and work piece material, in which there is increase in the intensity of the electric field in the volume between the electrodes. At a certain gap the intensity of electric field becomes greater than the strength of the dielectric (at least in some point (s)), which breaks, allowing current to flow between the two electrodes. This current flow creates spark 
and due to which heat is generated. This thermal energy generates a channel of plasma between the cathode and anode at a temperature in the range of 8000 to $12,000^{\circ} \mathrm{C}$ or as high as $20,000^{\circ} \mathrm{C}$ initialising a substantial amount of heating and melting of material at the surface of each pole. When the pulsating direct current supply occurring at the rate of approximately $20,000-30,000 \mathrm{~Hz}$ is turned off, the plasma channel breaks down. This causes a sudden reduction in the temperature allowing the circulating dielectric fluid to implore the plasma channel and flush the molten material from the pole surfaces in the form of microscopic debris [3].

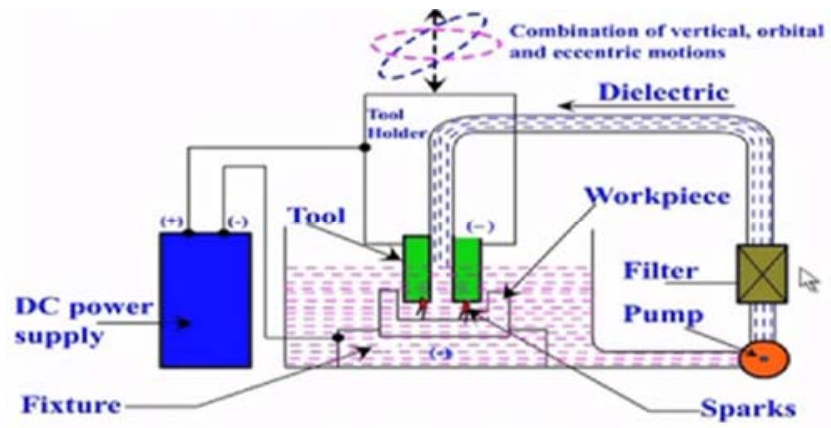

Fig. 1. Schematic Diagram of EDM. [4].

\section{Literature Review}

Shabgard et al. [2] investigated on the influence of Electrical Discharge Machining (EDM) input parameters on the characteristics of the EDM process. They studied process characteristics included machining features, embracing material removal rate, tool wear ratio, and arithmetical mean roughness of AISI H13 tool steel as workpiece. The experiments performed under the designed full factorial procedure, and the considered EDM input parameters included pulse on-time and pulse current. The increase in pulse on-time led to the increase in the material removal rate, surface roughness. The increase in pulse current led to the sharp increase in the material removal rate and surface roughness. The tool wear ratio decreased by the increase of pulse on-time, and increased by the increase in the pulse current.

Rehman et al. [5] presented the experimental investigation of the machining characteristics of austenitic stainless steel 304 through electric discharge machining. The effectiveness of the EDM process with stainless steel was evaluated in terms of the removal rate (MRR), the Tool Wear Rate (TWR.) and the surface roughness of the work-piece produced. The TWR increases with peak ampere until 150 microsec pulse-on time. From the experimental results no tool wear condition is noted for copper electrode at long pulse-on time with reverse polarity. The optimal pulse-on time is changed with high ampere.

$P$. Janmanee et al. [6] evaluated the performance of different electrode materials like graphite, copper-graphite and copper-tungsten in EDM of tungsten carbide. The important parameters were discharge current, pulse on time, pulse off time, open-circuit voltage and electrode polarity. Their investigation concluded that MRR increases with the discharge current intensity and graphite electrode gives the most MRR but it gives high electrode wear ratio.

S. L. Chen et al. [7] studied about various parameters of EDM like electrode material, pulse duration, discharge current and polarity using two materials namely silicon carbide and tungsten carbide as work piece and copper and copper tungsten as a tool material. They concluded that MRR is directly proportional to current and pulse duration, Electrode wear increased up to $80 \mu$ s then started decreasing with increase in pulse duration. They came into conclusion that Copper is better than copper tungsten as an electrode material due to homogeneous wear ratio.

\subsection{Objective of the Present Work}

The objective of the present work is summarized below-

- Selection of process variables viz. Intensity of current, Pulse-on-time \& Pulse-off-time in Die-Sink-EDM for machining of En-19 alloy steel and Nickel Plated En19.

- To investigate the Effect of tool electrode $\mathrm{Cu}$ on MRR and TWR.

- To develop an empirical model for Intensity of current, Pulse-on-time \& Pulse-off-time for machining of En-19 alloy steel using response surface method

- To verify the lack of fit of the proposed model using analysis of variance (ANOVA).

\subsection{Scope of the Project}

There is a widespread scope for project with the machining parameters like current, pulse on time and pulse off time.

- The work piece material used for study is En-19 and nickel plated En-19 alloy steel.

- EDM die sinking type machine is used to carry out the experimentation work.

- The tool electrodes used is Copper.

- Commercial grade EDM oil is used as a dielectric medium.

- The effect MRR and TWR are investigated.

\section{Materials and Methodology}

\subsection{Tool Material}

In this experiment copper having $7 \mathrm{~mm}$. machining diameter was used as a tool electrode. The important factors in selecting copper is its high stock metal removal, stability under sparking condition, wear comparability with graphite, it yields a finer surface finish, easy obtainability, consistency in quality and low in cost. Copper has melting point which is only about $1100^{\circ} \mathrm{C}$.

\subsection{Workpiece Material}

The workpiece material chosen was En-19 and Nickel Plated En-19. EN19 offers good ductility and shock resisting properties combined with resistance to wear. With these characteristics it is a popular high tensile engineering steel with a tensile of $850 / 1000 \mathrm{~N} / \mathrm{mm}^{2}$. At low temperatures 
EN19 has reasonably good impact properties.

\subsection{Methodology}

Response surface methodology (RSM) is used which is a collection of mathematical and statistical techniques that are useful for modeling and analysis of problems in which output or response is influenced by several variables. It is used to develop the relationship between a response of interest, $y$, and a number of associated control (or input) variables denoted by $\mathrm{x} 1, \mathrm{x} 2, \ldots ., \mathrm{xk}$.

Suppose $X_{1}$ and $X_{2}$ are the factors or parameters of interest of the process and ' $\mathrm{Y}_{\mathrm{i}}$ ' is the maximum yield of the process then the yield is a function of levels of $X_{1}$ and $X_{2}$ i.e.

$$
\mathrm{Y}_{\mathrm{i}}=\mathrm{f}\left(\mathrm{X}_{1}, \mathrm{X}_{2}\right)+\mathrm{e}_{\mathrm{i}}
$$

where ' $e_{i}$ ' represents the noise or error observed in the response $\mathrm{Y}_{\mathrm{i}}$. If we denote the expected response by

$$
\mathrm{E}\left(\mathrm{Y}_{\mathrm{i}}\right)=\mathrm{f}\left(\mathrm{X}_{1}, \mathrm{X}_{2}\right)=\eta
$$

Then the surface represented by

$$
\eta=f\left(X_{1}, X_{2}\right)
$$

is called response surface.

If there is curvature in the system, then a polynomial of higher degree must be used, such as the second-order model given in equation 4

$$
Y_{0}=\beta_{0}+\sum_{i=1}^{k} \beta_{i} x_{i}+\sum_{i=1}^{k} \beta_{i i} x_{i} x_{i}+\sum_{i>j} \sum \beta_{i j} x_{i} x_{j}+e_{i}
$$

Box-Behnken design is a response surface methodology (RSM) design that requires only three levels to run an experiment. It is a special 3-level design because it does not contain any points at the vertices of the experiment region. This could be advantageous when the points on the corners of the cube represent level combinations that are prohibitively expensive or impossible to test because of physical process constraints [27].

\subsection{Design Matrix}

In this study, three machining parameters were selected as control factors and each parameter was designed to have three levels denoted by 1,2 and 3 respectively. The experiments are planned using BBD in the design of experiments (DOE), which helps in reducing the number of experiments. The total 15 experimental runs were conducted with each tool on the workpiece and results of MRR and TWR was calculated. The process variables with their units and notations are shown in the Table 1 below.

Table 1. Parameters and Levels.

\begin{tabular}{llllll}
\hline MACHINING & UNI & \multicolumn{3}{l}{ RANGE AND LEVELS } \\
\cline { 5 - 6 } PARAMETER & T & -1 & 0 & +1 \\
\cline { 1 - 3 } Pulse on time & $\mu \mathrm{s}$ & & 10 & 40 & 70 \\
Pulse off time & $\mu \mathrm{s}$ & 2 & 4 & 6 \\
Current & $\mathrm{A}$ & 5 & 10 & 15 \\
\hline
\end{tabular}

\subsection{Machine Used}

The experimentation was conducted using EDM, model SAVITA 4631 (Die sinking type) having following specifications.

Table 2. Machine Specifications.

\begin{tabular}{llll}
\hline S. N. & TYPES & Unit & $\mathbf{4 6 3 1 1}$ \\
\hline 1 & Work tank dimensions & $\mathrm{mm}^{3}$ & $600 * 370 * 250$ \\
2 & Table size & $\mathrm{mm}^{2}$ & $350 * 200$ \\
3 & X-Axis Travel & $\mathrm{mm}$ & 200 \\
4 & Y-Axis Travel & $\mathrm{mm}$ & 120 \\
5 & Z-Axis Travel & $\mathrm{mm}$ & 150 \\
6 & Maximum Job Height & $\mathrm{mm}$ & 140 \\
7 & Maximum Electrode Weight & $\mathrm{kg}$ & 50 \\
8 & Maximum Job Weight & $\mathrm{kg}$. & 150 \\
9 & Dielectric Tank Capacity & $\mathrm{Lt}$. & 100 \\
10 & Machine Weight & $\mathrm{kg}$ & 450 \\
11 & Gross weight & $\mathrm{kg}$ & 600 \\
12 & Day Light & $\mathrm{mm}$ & 410 \\
13 & Throat & $\mathrm{mm}$ & 250 \\
14 & Overall Dimensions & $\mathrm{m}^{3}$ & $0.8 * 0.8 * 1.8$ \\
\hline
\end{tabular}

\section{Experimentation}

\subsection{Experimental Procedure}

1) Experiment was conducted with negative polarity of electrode. The electrode copper was taken. The diameter of electrode is measured with a micrometer. It was made sure its dimension is according to specification.

2) An initial mass is measured with precision balance. The electrode mass value and the work piece mass value were jotted.

3) The work material En-19 was mounted on the T-slot table and positioned at the desired place and clamped. The electrode was clamped on the tool holder, and its alignment was checked.

4) The parameters of the experiment were set regarding Table (1)

5) The time was set as 7 minutes for the machining of all work materials. Finally, switches 'ON' for operating the desire discharge current values.

6) After machining operation, the electrode was taken out and weighed again on weighing balance. Also the mass value of work piece was taken after machining.

7) The same experiment was repeated with Nickel Plated En-19 workpiece. This experiment is done 15 times for each workpiece. The data was fed to the MINITAB where calculation and analysis of results is done.

\subsection{MRR and TWR Evaluation}

The material MRR has been calculated by taking the difference between the weight of the work piece before and after machining to the machining time.

$$
\mathrm{MRR}=\frac{W b-W a}{t}
$$

Where,

- $\mathrm{Wb}=$ Weight of work piece before machining in gm 
- $\mathrm{Wa}=$ Weight of work piece after machining in gm

- $\mathrm{t}=$ Machining time in minutes

TWR is calculated in the same fashion by taking the difference of weight of the tool before and after machining to the machining time.

$$
\mathrm{TWR}=\frac{W b t-W a t}{t}
$$

Where,

- $\mathrm{Wbt}=$ Weight of the tool before machining in gm.

- Wat=Weight of the tool after machining in gm.

- $\mathrm{t}=$ Machining time in minutes

\section{Results and Discussion}

For interpreting the significant effect of the parameters, a statistical software program called MINITAB version 16 has been used. The experimental results from the tables were analyzed using ANOVA, which is used for identifying the factors significantly affecting the performance measures. The analysis was carried out for the significance level of $\alpha=0.1$ i.e. for a confidence level of $90 \%$. The sources with the $\mathrm{p}$ value less than 0.1 are considered to have a statistically significant.

a) Results of MRR for En-19

Table 3. Estimated Regression Coefficients for MRR

\begin{tabular}{lllll}
\hline Terms & Coeff. & SE Coeff. & T test & P value \\
\hline $\mathrm{C}$ & -0.057434 & 0.152702 & -0.376 & 0.722 \\
$\mathrm{I}$ & 0.036797 & 0.018193 & 2.023 & $0.099 *$ \\
$\mathrm{~T}_{\text {on }}$ & -0.000859 & 0.002512 & -0.342 & 0.746 \\
$\mathrm{~T}_{\text {off }}$ & -0.032453 & 0.045483 & -0.714 & 0.507 \\
$\mathrm{I}^{*} \mathrm{I}$ & -0.001527 & 0.000779 & -1.959 & $0.107 *$ \\
$\mathrm{~T}_{\text {on }} * \mathrm{~T}_{\text {on }}$ & -00000027 & 0.000022 & -1.244 & 0.269 \\
$\mathrm{~T}_{\text {off }} * \mathrm{~T}_{\text {off }}$ & 0.001461 & 0.004871 & 0.300 & 0.776 \\
$\mathrm{I}^{*} \mathrm{~T}_{\text {on }}$ & 0.000194 & 0.000125 & 1.558 & 0.180 \\
$\mathrm{I}^{*} \mathrm{~T}_{\text {off }}$ & -0.000529 & 0.001872 & -0.283 & 0.789 \\
$\mathrm{~T}_{\text {on }} * \mathrm{~T}_{\text {off }}$ & 0.000887 & 0.000312 & 2.843 & $0.036 *$ \\
\hline
\end{tabular}

$\mathrm{S}=0.0374411 \mathrm{R}-\mathrm{Sq}=93.32 \% \mathrm{R}-\mathrm{Sq}(\mathrm{pred})=0.00 \% \mathrm{R}-\mathrm{Sq}(\mathrm{adj})=81.28 \%$

From the ANOVA Table (3) above, again, small $\mathrm{P}$ values for model terms indicate that their contribution is significant to the model. Table shows that, the main effect of current is significant. However, it shall not be interpreted as pulse off-time and pulse off time do not have any effect on the MRR. Rather it shall be interpreted as pulse off-time and pulse off time has less significance on the response variable for our experimental and confidence level. The quadratic terms current*current and interaction terms pulse on time*pulse off time contributed significantly to the TWR at $90 \%$ confidence level.

Thus, the final model correlating MRR with machining parameters is found as follows:

$$
\begin{aligned}
\text { MRR }=- & 0.057434+0.036797 * \mathrm{I}-0.001527 * \mathrm{I} * \mathrm{I}+ \\
& 0.000887 * \text { Ton } * \text { Toff }
\end{aligned}
$$

Further from table, the $\mathrm{R}^{2}$ value of $93.32 \%$ indicates that, the variation in the response can be predicted $93 \%$ correctly by using the above model developed for $90 \%$ confidence interval.



Fig. 2. Main effect plot of MRR for En-19.

The graph shown in figure 2 shows that MRR increasing proportionately with the intensity of the current. It is found that, at the current of $15 \mathrm{~A}, \mathrm{MRR}$ is found to be the highest than the rest of 2 levels. This increase of MRR with current is due to the fact that an increase in discharge current increases the pulse energy which results in increase in the rate of melting and evaporation [8].

The graph reveals that on increasing the pulse on time, MRR goes on increasing. This event is due to the increase of the discharge energy of the plasma channel as well as the increase in the period of transferring of this energy into the electrodes resulting in the formation of a bigger molten material crater on the workpiece resulting higher MRR [2].

It is also evident that on increasing the pulse off time, MRR goes on increasing. It is because of correct flushing of the debris with sufficient pulse off time duration; which would otherwise make the spark contaminated and unstable, thus decreasing MRR [8].

b) Results of TWR for En-19

Table 4. Estimated Regression Coefficients for TWR.

\begin{tabular}{lllll}
\hline Terms & Coeff. & SE Coeff. & T test & P value \\
\hline $\mathrm{C}$ & -0.052201 & 0.032400 & -1.611 & 0.168 \\
$\mathrm{I}$ & 0.010781 & 0.003860 & 2.793 & $0.038 *$ \\
$\mathrm{~T}_{\text {on }}$ & 0.000191 & 0.000533 & 0.359 & 0.734 \\
$\mathrm{~T}_{\text {off }}$ & 0.007472 & 0.009650 & 0.774 & 0.474 \\
$\mathrm{I}^{*} \mathrm{I}$ & -0.000228 & 0.000165 & -1.380 & 0.226 \\
$\mathrm{~T}_{\text {on }} * \mathrm{~T}_{\text {on }}$ & -0.000006 & 0.000005 & -1.363 & 0.231 \\
$\mathrm{~T}_{\text {off }} * \mathrm{~T}_{\text {off }}$ & -1.000248 & 0.001034 & -0.240 & 0.820 \\
$\mathrm{I}^{*} \mathrm{~T}_{\text {on }}$ & 0.000020 & 0.000026 & 0.748 & 0.488 \\
$\mathrm{I}^{*} \mathrm{~T}_{\text {off }}$ & -0.001258 & 0.000397 & -3.168 & $0.025 *$ \\
$\mathrm{~T}_{\text {on }} * \mathrm{~T}_{\text {off }}$ & 0.000046 & 0.000066 & 0.692 & 0.520 \\
\hline
\end{tabular}

$\mathrm{S}=0.00794412 \mathrm{R}-\mathrm{Sq}=89.27 \% \mathrm{R}-\mathrm{Sq}(\mathrm{pred})=0.00 \% \mathrm{R}-\mathrm{Sq}(\operatorname{adj})=69.95 \%$

The main effects of Current can be deduced as having significant effect and interaction effect of "Current* Pulse off time" as second significant effect as per the table. Thus, the final model correlating Tool Wear Rate with machining parameters is found as follows:

$$
T W R=-0.052201+0.010781 * I-0.001258 * I * \text { Toff }
$$

Here process control variables are un-coded values. Further, from Table, it is evident that the model is adequate at 
$90 \%$ confidence level. The effectiveness of the model is checked by using the ' $\mathrm{R}^{2}$, value i.e. 0.89 near to 1 and hence the model is found to be effective. The validity of the model is reconsidered with the adjusted correlation coefficient i.e. ' $R{ }^{2}$ (adj.)'value $=0.699$, which is a measure of the variability of the observed output and can be explained by the factors along their factor interactions. Further to prove again the model to be considered adequate, the p-value has to be smaller than 0.10 at the $90 \%$ confidence interval.

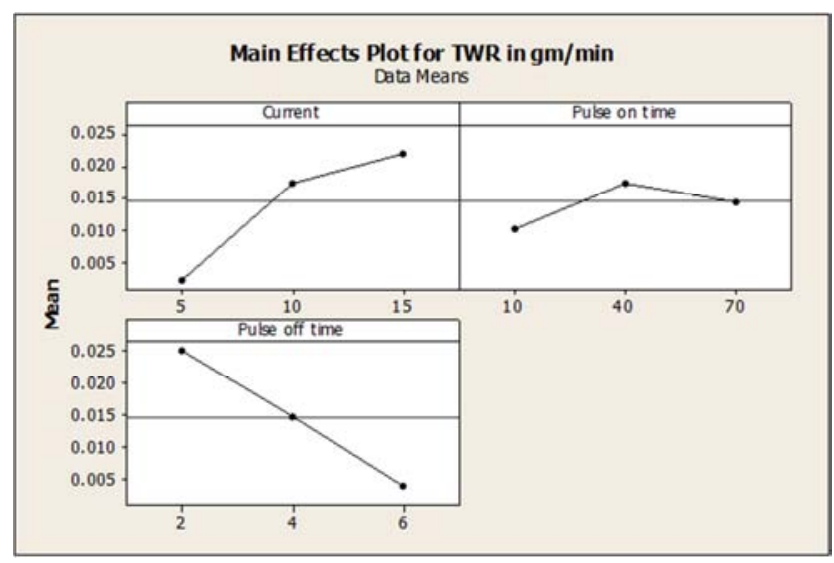

Fig. 3. Main effect plot of TWR for En-19.

The graph in figure 3 shows that at the current of $5 \mathrm{~A}$, TWR is found to be minimum. The reason is that, at low current a small quantity of heat is generated but by the increase in pulse current a substantial quantity of heat will be transferred into the electrodes. Furthermore as the pulse current increases, the discharge strikes the surface of the electrode more intensely and creates an impact force on the molten material in the crater and causes more molten material to be ejected out of the electrode [2].

The graph reveals that on increasing the pulse on time, TWR increases half the way and goes on decreasing. Moreover longer pulse on time can provide enough time for heavier positive ions attacking the cathode workpiece and hence removing more material from the work than the tool [9].

It is also evident that on increasing the pulse off time, TWR goes on decreasing. This is due to the fact that the long pulse duration provides decrease in temperature on the surface of electrode causes less wear on the electrode [10].

c) Results of MRR with Nickel Plated En-19

Table 5. Estimated Regression Coefficients for MRR.

\begin{tabular}{lllll}
\hline Terms & Coeff. & SE Coeff. & T test & P value \\
\hline $\mathrm{C}$ & -0.249757 & 0.125534 & -1.990 & 0.103 \\
$\mathrm{I}$ & 0.028567 & 0.014956 & 1.910 & 0.114 \\
$\mathrm{~T}_{\text {on }}$ & 0.004410 & 0.002065 & 2.136 & $0.086^{*}$ \\
$\mathrm{~T}_{\text {off }}$ & 0.056485 & 0.037391 & 1.511 & 0.191 \\
$\mathrm{I} * \mathrm{I}$ & -0.001283 & 0.000641 & -2.003 & $0.102^{*}$ \\
$\mathrm{~T}_{\text {on }} * \mathrm{~T}_{\text {on }}$ & -0.000064 & 0.000018 & -3.597 & $0.016^{*}$ \\
$\mathrm{~T}_{\text {off }} * \mathrm{~T}_{\text {off }}$ & -0.007859 & 0.004005 & -1.962 & $0.107^{*}$ \\
$\mathrm{I}^{*} \mathrm{~T}_{\text {on }}$ & 0.000291 & 0.000103 & 2.840 & $0.036^{*}$ \\
$\mathrm{I}^{*} \mathrm{~T}_{\text {off }}$ & 0.000696 & 0.001539 & 0.453 & 0.670 \\
$\mathrm{~T}_{\text {on }} * \mathrm{~T}_{\text {off }}$ & -0.000068 & 0.000256 & -0.265 & 0.802 \\
\hline
\end{tabular}

$\mathrm{S}=0.0307798 \mathrm{R}-\mathrm{Sq}=95.96 \% \mathrm{R}-\mathrm{Sq}(\mathrm{pred})=36.14 \% \mathrm{R}-\mathrm{Sq}($ adj $)=88.69 \%$
The main effects of "Pulse on time" can be deduced as having significant effect as per the table. Thus, the final model correlating Material Removal Rate with machining parameters is found as follows:

$$
\begin{aligned}
M R R & =-0.249757+0.004410 * \text { Ton }-0.001283 \\
& * I * I-0.000064 * \text { Ton } * \text { Ton }-0.007859 \\
& * \text { Toff } * \text { Toff }+0.000291 * I * \text { Ton }
\end{aligned}
$$

Further from Table (5), the $\mathrm{R}^{2}$ value of $95.96 \%$ indicates that, the variation in the response can be predicted $93 \%$ correctly by using the above model developed for $90 \%$ confidence interval.

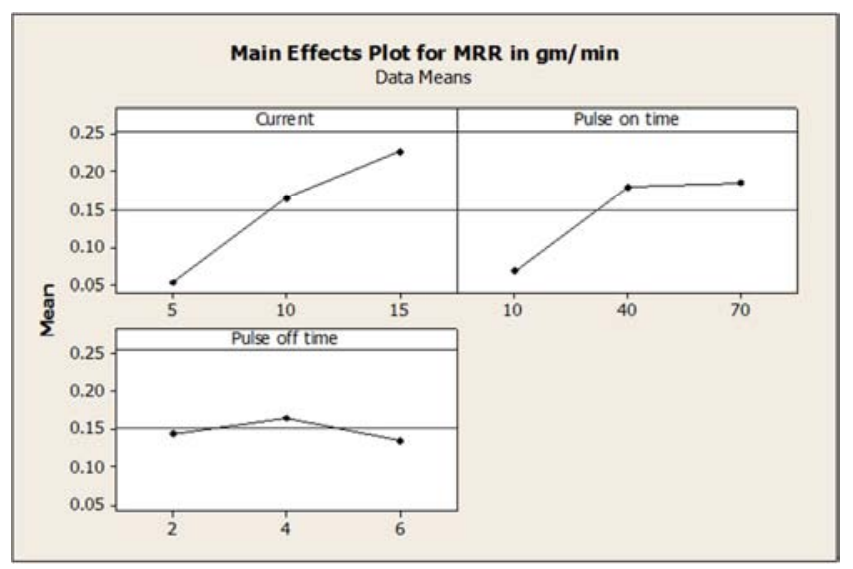

Fig. 4. Main effect plot of MRR for Nickel Plated En-19.

The graph in figure 4 shows that MRR increase proportionately with the current. It is found that, at the current of $15 \mathrm{~A}, \mathrm{MRR}$ is found to be the highest than the rest of 2 levels.

The graph reveals that on increasing the pulse on time, MRR goes on increasing. This event is due to the increase in the period of transferring of the discharge energy into the electrodes resulting in the formation of a bigger molten material crater on the workpiece resulting higher MRR.

It is also evident that on increasing the pulse off time, MRR goes on increasing. It is because of correct flushing of the debris with sufficient pulse off time duration; which would otherwise make the spark contaminated and unstable, thus decreasing MRR [7].

d) Results of TWR with Nickel Plated En-19

Table 6. Estimated Regression Coefficients for TWR.

\begin{tabular}{lllll}
\hline Terms & Coeff. & SE Coeff. & T test & P value \\
\hline $\mathrm{C}$ & 0.183414 & 0.108197 & 1.695 & 0.151 \\
$\mathrm{I}$ & -0.027748 & 0.012891 & -2.153 & $0.084 *$ \\
$\mathrm{~T}_{\text {on }}$ & -0.002643 & 0.001780 & -1.485 & 0.198 \\
$\mathrm{~T}_{\text {off }}$ & -0.011775 & 0.032227 & -0.365 & 0.730 \\
$\mathrm{I} * \mathrm{I}$ & 0.001252 & 0.000552 & 2.267 & $0.073 *$ \\
$\mathrm{~T}_{\text {on }} * \mathrm{~T}_{\text {on }}$ & 0.000033 & 0.000015 & 2.179 & $0 . .081^{*}$ \\
$\mathrm{~T}_{\text {off }} * \mathrm{~T}_{\text {off }}$ & 0.000871 & 0.003452 & 0.252 & 0.811 \\
$\mathrm{I}^{*} \mathrm{~T}_{\text {on }}$ & 0.000143 & 0.000088 & 1.613 & 0.168 \\
$\mathrm{I}^{*} \mathrm{~T}_{\text {off }}$ & 0.000930 & 0.001326 & 0.701 & 0.514 \\
$\mathrm{~T}_{\text {on }} * \mathrm{~T}_{\text {off }}$ & -0.000137 & 0.000221 & -0.619 & 0.563 \\
\hline
\end{tabular}

$\mathrm{S}=0.0265290 \mathrm{R}-\mathrm{Sq}=87.18 \% \mathrm{R}-\mathrm{Sq}(\mathrm{pred})=0.00 \% \mathrm{R}-\mathrm{Sq}(\mathrm{adj})=64.09 \%$ 
From the ANOVA Table (6) above, again, small P values for model terms indicate that their contribution is significant to the model. Table shows that, the main effect of current is significant. However, it shall not be interpreted as pulse on time and pulse off-time do not have any effect on the TWR. Rather it shall be interpreted as they have less significance on the response variable for our experimental and confidence level. Thus, the final model correlating TWR with machining parameters is found as follows:

TWR $=0.183414-.027748 * \mathrm{I}+0.001252 * \mathrm{I} * \mathrm{I}+0.000033 *$ Ton $*$ Ton

Further from Table (6), the ' $\mathrm{R}^{2}$, value of $87.18 \%$ indicates that, the variation in the response can be predicted $87 \%$ correctly by using the above model developed for $90 \%$ confidence interval.

The graph in figure 5 shows that at the current of $5 \mathrm{~A}$, TWR is found to be minimum. The reason is that, at low current a small quantity of heat is generated but by the increase in pulse current a substantial quantity of heat will be transferred into the electrodes. Furthermore as the pulse current increases, the discharge strikes the surface of the electrode more intensely and creates an impact force on the molten material in the crater and causes more molten material to be ejected out of the electrode [2].

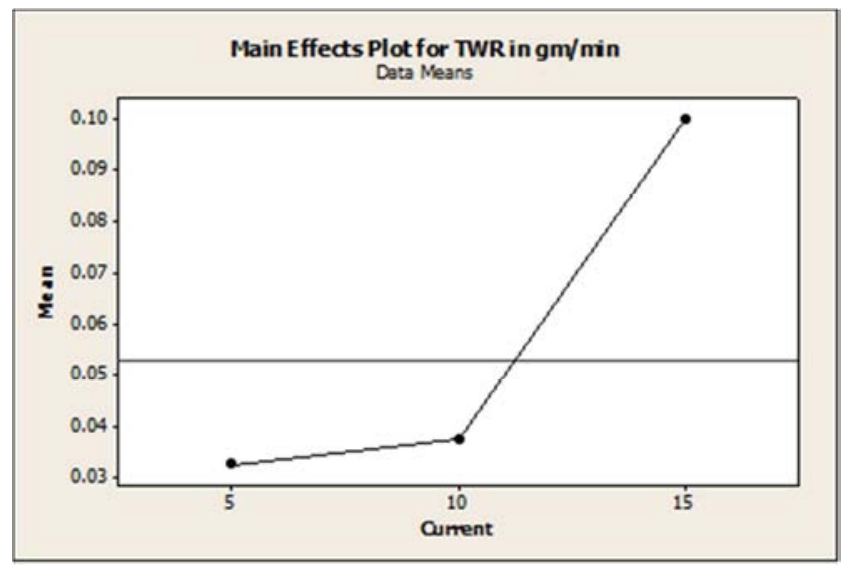

Fig. 5. Main effect plot of MRR for En-19.

Thus the individual effect of current was significant in TWR empirical response models for En-19 workpiece as well as Nickel Plated En-19 workpiece. In MRR empirical response models, the individual effect of current have the significant contributions in MRR empirical response models for En-19 workpiece while pulse on time was seen to have the significant contributions in TWR with Nickel Plated En19 workpiece.

\section{Conclusion}

Summarizing the main features the following conclusions can be drawn.

(1) The predicted machining performance values match the experimental values reasonably well; with $\mathrm{R}^{2}$ of
93.32 and $89.27 \%$ respectively for MRR and TWR with En-19 workpiece and $95.96 \%$ and $87.18 \%$ respectively for the MRR and TWR with Nickel Plated En-19 workpiece.

(2) It has been observed that MRR as well as TWR goes on increasing with the current.

(3) It was observed that MRR goes on increasing with pulse on time for both workpiece and while TWR goes on increasing with pulse on time till halfway and goes on decreasing for both workpiece.

(4) It has also been seen that MRR goes on increasing with pulse off time while TWR kept on decreasing with pulse off time.

\section{References}

[1] H S Payai, B L Sethi, "Non-conventional Machining Processes as Viable Alternatives for Production With Specific Reference to Electrical Discharge Machining", J SCI IND RES VOL 62, JULY 2003.

[2] Shabgard M, Mirsadegh S, Samad O, "Influence of Input Parameters on the Characteristics of the EDM Process", Journal of Mechanical Engineering 57 (2011) 9, 689-696.

[3] K. H. Ho, S. T. Newman, "State of the art electrical discharge machining (EDM)", International Journal of Machine Tools \& Manufacture 43 (2003) 1287-1300.

[4] Dr. A.K. Sharma, http://nptel.iitm.ac.in/ Department of Mechanical Engineering, IIT Roorkee.

[5] Rahman M. M, Khan M. A. R., Kadirgama K., Noor M. M., Baker R. A., "Experimental Investigation into Electrical Discharge Machining of Stainless Steel", Journal of Applied Sciences, 2011, vol. 3, pp. 549-554.

[6] M. M. Pawade, S. S. Banwait, "A Brief Review of Die Sinking Electrical Discharging Machining Process towards Automation", American Journal of Mechanical Engineering, 2013, Vol. 1, No. 2, 43-49.

[7] S. L. Chen, M. H. Lin, S. F. Hsieh and S. Y. Chiou.; "The characteristics of cutting pipe mechanism with multi-electrode in EDM", Journal of material processing technology Vol, 203, (2008), pp. 461-464.

[8] M. S. Sohani. V. N. Gaitonde. B. Siddeswarappa. A. S. Deshpande, "Investigations into the effect of tool shapes with size factor consideration in sink electrical discharge machining (EDM) process", International Journal of Advanced Manufacturing Technology (2009) 45: 1131-1145.

[9] S. Assarzadeh, M. Ghoreishi, "Statistical modeling and optimization of process parameters in electro-discharge machining of cobalt-bonded tungsten carbide composite (WC/6\%Co)", The Seventeenth CIRP Conference on Electro Physical and Chemical Machining (ISEM), Procedia CIRP 6 (2013) 463-468.

[10] B. Mohan, A. Rajadurai, K. G. Satyanarayana, "Electric discharge machining of $\mathrm{Al}-\mathrm{SiC}$ metal matrix composites using rotary tube electrode", Journal of Materials Processing Technology 153-154 (2004) 978-985. 